\title{
Effects of formoterol and ipratropium bromide in COPD: a 3-month placebo-controlled study
}

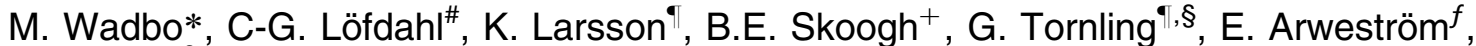 \\ T. Bengtsson ${ }^{\S}, \mathrm{K}$. Ström**, a study initiated by The Swedish Society of Respiratory Medicine
}

\begin{abstract}
Effects of formoterol and ipratropium bromide in COPD: a 3-month placebo-controlled study. M. Wadbo, C-G.Löfdahl, K. Larsson, B.E. Skoogh, G. Tornling, E. Arweström, T. Bengtsson, K. Ström, a study initiated by The Swedish Society of Respiratory Medicine. (C) ERS Journals Ltd 2002.

ABSTRACT: The aim of this study was to compare the effects of formoterol, ipratropium bromide and a placebo on walking distance, lung function, symptoms and quality of life (QoL) in chronic obstructive pulmonary disease (COPD) patients.

A total of 183 patients (mean age $64 \mathrm{yrs}, 86$ female) with moderate-to-severe nonreversible COPD participated in this randomised, double-blind, parallel-group study. After a 2-week placebo run-in, patients were randomised to formoterol Turbuhaler $\AA 18 \mu \mathrm{g}$ b.i.d. (delivered dose), ipratropium bromide $80 \mu \mathrm{g}$ t.i.d. via a pressurised metered dose inhaler, or placebo for 12 weeks. Inhaled short-acting $\beta_{2}-$ agonists were allowed as relief medication and inhaled glucocorticosteroids were allowed at a constant dose. The primary variable was walking distance in the shuttle walking test (SWT). Baseline mean SWT distance was 325 m, mean forced expiratory volume in one second (FEV1) was $40 \%$ predicted.

Clinically significant improvements in SWT $(>30 \mathrm{~m}$ ) were seen in 41,38 and $30 \%$ of formoterol, ipratropium and placebo patients, respectively (not significant). Mean increases from run-in were 19,17 and $5 \mathrm{~m}$ in the formoterol, ipratropium and placebo groups, respectively. Both active treatments significantly improved FEV1, forced vital capacity, peak expiratory flow and daytime dyspnoea score compared with placebo. Formoterol reduced relief medication use compared with placebo. Neither active treatment improved QoL.

Formoterol and ipratropium improved airway function and symptoms, without significant improvements in the shuttle walking test.
\end{abstract}

Eur Respir J 2002; 20: 1138-1146.
Depts of Respiratory Medicine in * Malmö General University Hospital, Malmö, "\# Lund University Hospital, Lund, Karolinska Hospital, Stockholm, ${ }^{+}$Sahlgrenska University Hospital, Gothenburg, ${ }^{\$}$ AstraZeneca R\&D, Lund, ${ }^{f}$ Draco Läkemedel AB, Lund, **Blekinge Hospital, Karlskrona, Sweden.

Correspondence: K. Ström

Dept of Respiratory Medicine

Norrland University Hospital

S-90185 Umeå

Sweden

Fax: 46090141369

E-mail: kerstin.strom.@vll.se

Keywords: Chronic obstructive pulmonary disease

formoterol

ipratropium

randomised controlled trial

shuttle walking test

Received: December 102001

Accepted after revision: June 162002
Chronic obstructive pulmonary disease (COPD) is characterised by slowly developing airway obstruction, with increasing impairment of exercise performance due to dyspnoea. The pharmacological therapy of COPD is mainly focused on the use of bronchodilators such as anticholinergics and $\beta_{2}$-agonists, and the role of inhaled glucocorticosteroids (GCS) is currently being discussed [1-5]. The goal of treatment is to improve exercise capacity, lung function and arterial blood gas tensions, and to reduce the symptoms of dyspnoea. However, studies have shown, that the effects of bronchodilators on these different outcome variables are not always well correlated [6, 7].

Long-acting bronchodilators are effective in the treatment of asthma, reducing symptoms and decreasing exacerbations [8]. In COPD, the long-acting $\beta_{2}$-agonists are less well studied. One study of salmeterol showed symptom reduction and lung function improvement [9] and some improvement in quality of life (QoL) when the drug was used in low doses [10]. Formoterol is a $\beta_{2}$-agonist with a long-acting bronchodilating effect in asthma lasting $12 \mathrm{~h}$ but unlike salmeterol, it has an onset of action as fast as salbutamol [11]. However, formoterol has been subject to few long-term studies in COPD. Ipratropium bromide has an established position in the treatment of COPD and has been suggested as the first choice of treatment for this condition $[1,3]$.

Exercise capacity of patients with COPD has been studied using walking tests such as the 6- or 12-min walking test. These tests are dependent on motivation and encouragement and are therefore difficult to standardise. The shuttle walking test (SWT) developed by SINGH and co-workers [12, 13] is externally paced and is less dependent on encouragement from the test leader. It is also incremental, pushing the patient to a symptom-limited maximum performance. A pilot study of the SWT in COPD patients, comparing formoterol and placebo, showed good reproducibility and an acute improvement in exercise capacity after formoterol inhalation.

The primary aim of this study was to compare the effect of formoterol, ipratropium bromide and placebo on walking distance using the SWT in patients with advanced COPD, with no or little reversibility as reflected by an acute reversibility test. The underlying 
hypothesis was that even a small bronchodilating effect in these severely obstructive patients would improve exercise capacity. Furthermore, it was assumed that even a small improvement in the exercise capacity would affect the patients' experience of symptoms and QoL. Secondary aims were to evaluate self-reported COPD symptoms and intake of relief medication, arterial blood gases, and lung function variables such as peak expiratory flow (PEF), forced expiratory volume in one second (FEV1) and forced vital capacity (FVC).

\section{Patients and methods}

\section{Study design}

This study was a double-blind, randomised, placebo-controlled, parallel-group study carried out at 14 centres in Sweden. An initial 2-week, singleblind, run-in period, during which patients took placebo, was followed by a 12-week, double-blind, treatment period during which patients received either formoterol, ipratropium bromide or placebo. In order to have comparable groups, stratification was performed according to the walking distance achieved at the randomisation visit. Patients with a walking distance $\leqslant 300 \mathrm{~m}$ were sequentially assigned the lowest randomisation number and patients with a walking distance $>300 \mathrm{~m}$ the highest available randomisation number. The $300 \mathrm{~m}$ limit was chosen after performance of the pilot study mentioned above. The trial was approved by the Research Ethics Committee in Lund and the Swedish Medical Products Agency, and was conducted according to the principles of the Declaration of Helsinki and Good Clinical Practice. Written informed consent was obtained from all patients before enrolment.

\section{Patients}

The study included male and female outpatients, aged 40-75 yrs, current smokers or former smokers with a history of $>10$ pack-yrs and with a diagnosis of COPD as defined by the European Respiratory Society [2]. Furthermore, the patients had to have a history of reduced exercise capacity due to dyspnoea on exertion. To be eligible for the study, the patients had to have an FEV $1<60 \%$ of predicted normal value and a quotient $\mathrm{FEV} 1 / \mathrm{FVC}<70 \%$. Furthermore, the reversibility had to be $<12 \%$ of predicted normal value, $45 \mathrm{~min}$ after inhalation of $120 \mu \mathrm{g}$ ipratropium bromide via pressurised metered dose inhaler (pMDI) or $27 \mu \mathrm{g}$ formoterol via Turbuhaler $\mathbb{R}$ given on two separate occasions 1-3 days apart. The oxygen tension in arterial blood $\left(\mathrm{Pa}, \mathrm{O}_{2}\right)$ at rest at the second enrolment needed to be $>7.3 \mathrm{kPa}$. Patients with adult asthma and patients on long-term oxygen therapy were excluded.

\section{Treatment}

After a 2-week, single-blind, placebo run-in period, eligible patients were randomised to one of the following treatments for 12 weeks: formoterol Turbuhaler $18 \mu \mathrm{g}$ b.i.d. and placebo pMDI t.i.d., or ipratropium bromide pMDI $80 \mu \mathrm{g}$ t.i.d. and placebo Turbuhaler $\AA$ b.i.d., or placebo pMDI t.i.d. and placebo Turbuhaler $\mathbb{R}$ b.i.d. The inhalation from the study drug inhalers was performed in accordance with the manufacturers' recommendations. The patient practised inhalation techniques with placebo drug in both study inhalers at each study visit under the supervision of a study nurse.

An inhaled short-acting $\beta_{2}$-agonist was used as relief medication. No other bronchodilator medication was permitted during the study. Inhaled and oral GCS as well as mucolytics were allowed if kept at a constant dosage during the study. Other concomitant medications considered necessary for each patient's well-being could be given at the investigator's discretion.

\section{Assessments}

Demographic characteristics and medical history were recorded at enrolment to the study. Clinical assessments were performed at enrolment, 1 day after enrolment, at the end of the run-in period, and after 4,8 and 12 weeks of double-blind treatment. All assessments were performed in the morning and using the same equipment. The patient was advised not to use $\beta_{2}$-agonists and to avoid strenuous activity for $6 \mathrm{~h}$ before the assessments. The patient was also instructed not to smoke for $1 \mathrm{~h}$ before the clinic visit and smoking was not allowed during the visits.

The SWT required the patient to walk up and down a $10 \mathrm{~m}$ course. The course was identified by two cones inset $0.5 \mathrm{~m}$ from either end. The speed at which the patient walked was dictated by an audio signal played on a cassette tape. Patients listened to taped standardised instructions before starting. After each minute, the speed of walking was increased by a small increment. The test was discontinued if the patient was too breathless to continue or failed to reach the next cone in time [12]. The pulse was taken and the Borg dyspnoea score [14] was recorded after a 5-min rest, both before and immediately after the patient had completed the SWT.

FEV1 and FVC were measured at each clinic visit

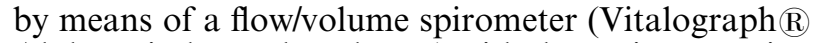
Alpha, Vitalograph Ltd, UK) with the patient wearing a noseclip and seated for each measurement. Spirometry was performed three times at each assessment and the highest values for FEV1 and FVC were recorded. The chosen values were not to exceed the second best value by $>200 \mathrm{~mL}$. Spirometry was performed before the SWT.

To assess blood gas tensions, $\mathrm{Pa}, \mathrm{O}_{2}$, the carbon dioxide tension in arterial blood, $\mathrm{pH}$ and base excess, an arterial blood sample was drawn from the radial artery after $20 \mathrm{~min}$ of rest following the SWT. Blood gas tensions were assessed at enrolment, at randomisation and after 12 weeks of treatment.

The St Georges Respiratory Questionnaire (SGRQ), in Swedish, was used to assess health status [15]. This self-administered questionnaire was filled in by the 
patient at the enrolment visit (as training), at randomisation and after 12 weeks of treatment.

Patients were provided with a Vitalograph peakflow meter and asked to record PEF every day upon waking and in the evening. These measurements were made before inhalation of the study medication and, if possible, at least $6 \mathrm{~h}$ after use of relief medication. The daytime and night-time severity of COPD symptoms was assessed separately and recorded in the diary cards. The symptoms of dyspnoea, cough and disturbance of sleep were rated on a $0-4$ scale, where 0 was no symptoms and 4 was severe symptoms. Intake of study medication and use of relief medication were also recorded.

Information about adverse events was obtained by asking the patient "Have you had any health problems or symptoms since the last visit?". The onset, duration, severity and outcome of each adverse event were recorded.

\section{Statistics}

The end-point for all statistical analyses was the change from baseline to end-of-treatment. For variables scored at the clinic visits, baseline was the value from the randomisation visit and end-of-treatment the value after 12 weeks treatment. The last value extended principle was used to replace missing values for withdrawn patients who had performed at least one post-randomisation visit. For diary card variables, baseline was the mean over the last 7 days of the run-in period and end-of-treatment was the mean over the last 60 days of the treatment period. Period means were computed using data from all registered days within the period.

Treatments were compared using an analysis of variance model with fixed factors treatment, centre and interaction treatment by centre. Baseline was used as a covariate. Treatment effects were weighted over centres according to precision. Multiplicative models were used for FEV1 and FVC, and additive models for all other variables. The influence of other baseline characteristics was checked by including them as extra covariates, one at a time. Subgroup analysis by stratification according to walking distance at randomisation $(\leqslant 300 \mathrm{~m}$ or $>300 \mathrm{~m})$, sex, smoking habits and use of inhaled GCS was performed as separate analyses in each stratum. Time trends were investigated by analysis of each successive point, assuming equal variance over time. Withdrawal rates were compared between treatments with a Pearson's Chi-squared test.

Bronchodilator effects in COPD are often small and it could be questioned whether small changes in physiological variables have any importance for the patient. In an attempt to define a clinically significant lower threshold for the differences found between treatments in the main study variable "walking distance" in the individual patients in this trial, the differences $\geqslant 30 \mathrm{~m}$ from baseline were classified as clinically significant in the study plan. The proportion of patients with clinically significant changes in walking distance were compared with a Pearson's Chi-squared test.

All analyses were performed according to the intention-to-treat approach, i.e. included all patients that took at least one dose of study drug and had data from the relevant treatment period. All tests were twosided at a $5 \%$ significance level. A power calculation regarding the measurement of SWT was performed showing that with 45 patients in each group, there would be an $80 \%$ chance of detecting a true difference between two treatments of $30 \mathrm{~m}$ using a paired t-test at a 5\% significance level.

\section{Results}

A total of 183 patients were randomised: 61 patients received formoterol, 62 patients ipratropium bromide and 60 patients placebo. Patient characteristics are shown in table 1. Treatment groups were well matched with the exception of the numbers of current smokers, who were fewer in the ipratropium bromide group: 10 compared to 23 in the formoterol group and 18 in the placebo group. Some differences between treatment groups were also seen in the use of prestudy medication, fewer patients in the formoterol group (61\%) used inhaled GCS compared with both the ipratropium bromide group $(77 \%)$ and the placebo group $(75 \%)$.

The total number of withdrawals was $39(21 \%)$ : there were $17(28 \%)$ in the formoterol group, $6(10 \%)$ in the ipratropium bromide group and $16(27 \%)$ in the placebo group (table 2). The difference between the formoterol and ipratropium bromide groups in the number of withdrawals was statistically significant $(p<0.02)$. A point worth noting is that before entry to the study, 13 of the withdrawn patients in the formoterol group, three in the ipratropium bromide group and 11 in the placebo group had used ipratropium bromide.

Most of the patients who discontinued belonged to the $\leqslant 300 \mathrm{~m}$ stratum: 13 patients $(42 \%)$ of this stratum in the formoterol group, one $(3 \%)$ in the ipratropium bromide group and $11(34 \%)$ in the placebo group. The difference in distribution of withdrawals in this stratum between the groups was statistically significant $(p<0.002)$. In the other stratum, $>300 \mathrm{~m}$, the distribution was more even, four patients $(13 \%)$ in the formoterol group, five $(16 \%)$ in the ipratropium bromide group and five (18\%) in the placebo group, without a statistically significant difference.

\section{The shuttle walking test}

The mean walking distance in the SWT at randomisation was $325 \mathrm{~m}(60-710 \mathrm{~m})$. Ninety-three patients had a walking distance of $\leqslant 300 \mathrm{~m}$ and 90 patients had a walking distance of $>300 \mathrm{~m}$ (table 3 ). The baseline walking distance was similar in the three treatment groups (table 1).

The individual distance walked, varied greatly 
Table 1. - Patient characteristics by treatment

\begin{tabular}{lccc}
\hline Variable & Placebo & $\begin{array}{c}\text { Formoterol } \\
\text { Turbuhaler }\end{array}$ & $\begin{array}{c}\text { Iptratropium bromide } \\
\text { pMDI }\end{array}$ \\
\hline Patients n & & 61 & 62 \\
Sex male/female & 60 & $33 / 28$ & $34 / 28$ \\
Age yrs & $30 / 30$ & $63.6(48-74)$ & $64.8(50-74)$ \\
BMI kg.m & $63.6(47-74)$ & $24.1(17-35)$ & $24.3(14-43)$ \\
Smoking habits current/former & $24.2(17-36)$ & $23 / 37$ & $10 / 51$ \\
COPD symptoms yrs & $18 / 41$ & $9.7(1-34)$ & $10.0(1-23)$ \\
FEV1 \% PN & $11.1(2-30)$ & $33.3(14.6-60.8)$ & $33.6(14.8-57.8)$ \\
FVC \% PN & $32.6(11.9-56.4)$ & $60.7(32.9-88.2)$ & $60.7(22.6-107.8)$ \\
Reversibility after ipratropium bromide \% PN & $59.4(14.6-90.7)$ & $5.52(-12.9-11.9)$ & $5.58(-11.0-11.7)$ \\
Reversibility after formoterol \% PN & $6.27(-0.6-11.4)$ & $5.75(-2.4-11.3)$ & $6.68(0.4-12.0)$ \\
Pa, $\mathrm{O}_{2} \mathrm{kPa}$ & $5.99(-0.5-11.9)$ & $9.6(7.8-12.7)$ & $9.4(7.7-12.3)$ \\
IgE kU·L & $9.5(7.5-11.5)$ & $31(1-789)$ & $45(1-347)$ \\
Walking distance at randomisation m & $30(1-593)$ & $319(70-670)$ & $324(90-710)$ \\
Mean dyspnoea score & $333(60-670)$ & $0.9(0-3)$ & $1.5(0-4)$ \\
Daytime dyspnoea score & $1.1(0-3)$ & $1.6(0.0-3.6)$ & $1.8(0.0-3.3)$ \\
Daytime cough score & $1.6(0.0-3.7)$ & $1.3(0.0-3.7)$ & $1.2(0.0-2.6)$ \\
\hline
\end{tabular}

Data are presented as mean value (range) unless otherwise stated. pMDI: pressurised metered dose inhaler; BMI: body mass index; COPD: chronic obstructive pulmonary disease; FEV1: forced expiratory volume in one second; FVC: forced vital capacity; \% PN: \% of predicted normal value; $\mathrm{Pa}_{\mathrm{a}} \mathrm{O}_{2}$ : oxygen tension in arterial blood; IgE: immunoglobulin $\mathrm{E}$.

among patients (tables 1 and 3). There was no statistically significant difference between the treatment groups after 12 weeks, although the distance was numerically lower in the placebo group (table 4). A small numerical improvement in walking distance was found compared with baseline: the distance increased by $19.2 \mathrm{~m}$ (95\% confidence interval (CI): 3.5-34.9) in the formoterol group, $17.5 \mathrm{~m}(2.2-32.8)$ in the ipratropium bromide group and $5.1 \mathrm{~m}(-10.9-21.0)$ in the placebo group (table 4). The percentage of patients in each group reaching a clinically significant improvement of $\geqslant 30 \mathrm{~m}$ after 12 weeks compared with baseline was $41 \%$ in the formoterol group, $38 \%$ in the ipratropium bromide group and 30\% in the placebo group.

In an ad hoc analysis 4 and 8 weeks after randomisation, there was a statistically significant difference of $29.9 \mathrm{~m} \mathrm{(95 \%} \mathrm{CI:} \mathrm{8.8-50.9)} \mathrm{between} \mathrm{the}$ formoterol and placebo groups seen after 4 weeks of treatment. Thereafter, no significant differences between the treatment groups were seen.

The influence of the stratification with regard to walking distance at randomisation is shown in figure 1 . The numbers of patients in the $\leqslant 300 \mathrm{~m}$ and $>300 \mathrm{~m}$ strata were similar. Numerically, the mean improvement in walking distance covered was

Table 2. - Number of patients and number of adverse events leading to withdrawal

\begin{tabular}{|c|c|c|c|}
\hline Withdrawal cause & Placebo & Formoterol Turbuhaler $\mathbb{R}$ & Ipratropium bromide $\mathrm{pMDI}$ \\
\hline Withdrawing patients & 17 & 16 & 6 \\
\hline Patients withdrawing due to adverse event & 15 & 16 & 6 \\
\hline Adverse events & 18 & 19 & 6 \\
\hline Deterioration of COPD & 6 & 3 & 3 \\
\hline Dyspnoea & 5 & 5 & 1 \\
\hline Pneumonia & 2 & 0 & 0 \\
\hline Coughing & 1 & 1 & 0 \\
\hline Respiratory tract infection & 0 & 2 & 0 \\
\hline Bronchitis & 0 & 0 & 1 \\
\hline Viral infection & 1 & 0 & 0 \\
\hline Infection & 1 & 0 & 0 \\
\hline Pharyngitis & 1 & 0 & 0 \\
\hline Fracture & 1 & 0 & 0 \\
\hline Pneumothorax & 0 & 1 & 0 \\
\hline Pruritus & 0 & 1 & 0 \\
\hline Rash & 0 & 1 & 0 \\
\hline Gastroenteritis & 0 & 1 & 0 \\
\hline Diarrhoea & 0 & 1 & 0 \\
\hline Abdominal pain & 0 & 1 & 0 \\
\hline Leucocytosis & 0 & 1 & 0 \\
\hline Rheumatoid arthritis & 0 & 1 & 0 \\
\hline Atrial fibrillation & 0 & 0 & 1 \\
\hline
\end{tabular}

Data are presented as n; COPD: chronic obstructive pulmonary disease; pMDI: pressurised metered dose inhaler. More than one reason for withdrawal could be recorded. 
Table 3. - Patient characteristics by treatment and walking distance at randomisation ( $\leqslant 300 \mathrm{~m}$ and $>300 \mathrm{~m})$

\begin{tabular}{|c|c|c|c|c|c|c|}
\hline \multirow{2}{*}{ Characteristic } & \multicolumn{2}{|c|}{ Placebo } & \multicolumn{2}{|c|}{ Formoterol Turbuhaler $₫$} & \multicolumn{2}{|c|}{ Ipratropium bromide pMDI } \\
\hline & $\begin{array}{c}\leqslant 300 \mathrm{~m} \\
32\end{array}$ & $\begin{array}{c}>300 \mathrm{~m} \\
28\end{array}$ & $\begin{array}{c}<300 \mathrm{~m} \\
31\end{array}$ & $\begin{array}{c}>300 \mathrm{~m} \\
30\end{array}$ & $\begin{array}{c}<300 \mathrm{~m} \\
30\end{array}$ & $\begin{array}{c}>300 \mathrm{~m} \\
32\end{array}$ \\
\hline Sex males/females & $13 / 19$ & $17 / 11$ & $16 / 15$ & $17 / 13$ & $13 / 17$ & 21/11 \\
\hline Age yrs & $64(51-74)$ & $63(47-74)$ & $65(53-74)$ & $62(48-74)$ & $67(57-74)$ & $62(50-74)$ \\
\hline $\mathrm{BMI} \mathrm{kg} \cdot \mathrm{m}^{-2}$ & $24(17-36)$ & $24(17-31)$ & $24(17-35)$ & $25(19-33)$ & $25(14-43)$ & $24(17-32)$ \\
\hline $\begin{array}{l}\text { Smoking habits } \\
\text { current/former }\end{array}$ & $7 / 25$ & $12 / 16$ & $11 / 20$ & $13 / 17$ & $7 / 23$ & $4 / 28$ \\
\hline FEV1 \% PN & $30(12-55)$ & $36(17-56)$ & $29(15-46)$ & $37(18-61)$ & $32(16-58)$ & $35(15-54)$ \\
\hline $\mathrm{FVC} \% \mathrm{PN}$ & $56(15-88)$ & $64(33-91)$ & $59(33-86)$ & $63(39-88)$ & $57(23-96)$ & $64(34-108)$ \\
\hline $\begin{array}{l}\text { Reversibility after } \\
\text { ipratropium } \\
\text { bromide } \% \text { PN }\end{array}$ & $6(1-11)$ & $6(-1-11)$ & $6(-3-12)$ & $5(-13-12)$ & $4(-11-12)$ & $7(0-11)$ \\
\hline $\begin{array}{l}\text { Reversibility after } \\
\text { formoterol } \% \mathrm{PN}\end{array}$ & $6(-1-12)$ & $7(1-12)$ & $5(-2-11)$ & $6(-2-11)$ & $7(2-10)$ & $7(0-12)$ \\
\hline$P \mathrm{a}, \mathrm{O}_{2} \mathrm{kPa}$ & $9.3(7.5-10.9)$ & $9.7(8.0-11.5)$ & $9.4(7.8-11.3)$ & $9.9(8.3-12.7)$ & $9.2(7.8-12.3)$ & $9.6(7.7-11.9)$ \\
\hline Walking distance $\mathrm{m}$ & $225(60-300)$ & $456(310-670)$ & $216(70-300)$ & $426(330-670)$ & $199(90-300)$ & $442(320-710)$ \\
\hline
\end{tabular}

Data are presented as mean value (range) unless otherwise stated. pMDI: pressurised metered dose inhaler; BMI: body mass index; FEV1: forced expiratory volume in one second; FVC: forced vital capacity; $\%$ PN: $\%$ of predicted normal value; $P$ a, $\mathrm{O}_{2}$ : oxygen tension in arterial blood.

approximately twice as large in the actively treated groups in the $\leqslant 300 \mathrm{~m}$ stratum, but this difference was not statistically significant. Thus, the main difference between active treatments and placebo was seen in patients walking $<300 \mathrm{~m}$ at baseline.

Subgroup analyses were also performed to evaluate if sex, smoking habits and use of GCS had any influence on the outcome of the SWT. No statistically significant influence was found. The influence of continuous variables such as age, duration of COPD, FEV1 and dyspnoea score at randomisation, reversibility to formoterol and ipratropium bromide respectively, and diurnal variation in PEF values during the last 7 days of run-in were also examined

Table 4.-Differences in study variables from baseline (randomisation) to 4, 8 and 12 weeks after randomisation, and adjusted mean changes from baseline to end-of-treatment, by treatment group

\begin{tabular}{|c|c|c|c|c|}
\hline \multirow[t]{2}{*}{ Variable } & \multicolumn{3}{|c|}{ Raw means (LVE) } & \multirow{2}{*}{$\begin{array}{l}\text { Adjusted means } \\
\text { End-of-treatment }\end{array}$} \\
\hline & 4 weeks & 8 weeks & 12 weeks & \\
\hline \multicolumn{5}{|l|}{ Walking distance $\mathrm{m}$} \\
\hline Placebo & 2.5 & 7.0 & 6.0 & 5.1 \\
\hline Formoterol & 27.5 & 18.0 & 20.4 & 19.2 \\
\hline Ipratropium bromide & 17.7 & 19.3 & 15.3 & 17.5 \\
\hline \multicolumn{5}{|c|}{ Dyspnoea after exercise (Borg) } \\
\hline Placebo & 0.25 & 0.32 & 0.47 & 0.55 \\
\hline Formoterol & -0.25 & -0.14 & -0.04 & 0.08 \\
\hline Ipratropium bromide & -0.08 & -0.22 & 0.18 & 0.25 \\
\hline \multicolumn{5}{|l|}{ FEV $1 \%$ of baseline } \\
\hline Placebo & 2.7 & 4.2 & 4.7 & 3.1 \\
\hline Formoterol & 19.5 & 19.1 & 16.7 & $16.9 *$ \\
\hline Ipratropium bromide & 11.3 & 12.5 & 10.1 & $10.7^{*}$ \\
\hline \multicolumn{5}{|l|}{ FVC $\%$ of baseline } \\
\hline Placebo & 3.2 & 6.6 & 6.6 & 4.4 \\
\hline Formoterol & 14.5 & 13.5 & 11.7 & $12.4^{*}$ \\
\hline Ipratropium bromide & 10.9 & 12.7 & 11.8 & $12.8^{*}$ \\
\hline \multicolumn{5}{|c|}{ Daytime breathlessness $(0-4)$} \\
\hline Placebo & -0.08 & -0.04 & -0.08 & 0.00 \\
\hline Formoterol & -0.35 & -0.25 & -0.22 & $-0.21 *$ \\
\hline Ipratropium bromide & -0.39 & -0.42 & -0.35 & $-0.29 *$ \\
\hline \multicolumn{5}{|l|}{ Daytime cough $(0-4)$} \\
\hline Placebo & -0.09 & -0.10 & -0.12 & -0.07 \\
\hline Formoterol & -0.27 & -0.24 & -0.13 & -0.18 \\
\hline Ipratropium bromide & -0.21 & -0.33 & -0.24 & $-0.26^{*}$ \\
\hline
\end{tabular}

\#: adjusted for centre and baseline effects. LVE: last value extended; FEV1: forced expiratory volume in one second; FVC: forced vital capacity. ${ }^{*}$ : significant difference versus placebo, $\mathrm{p}<0.05$. 


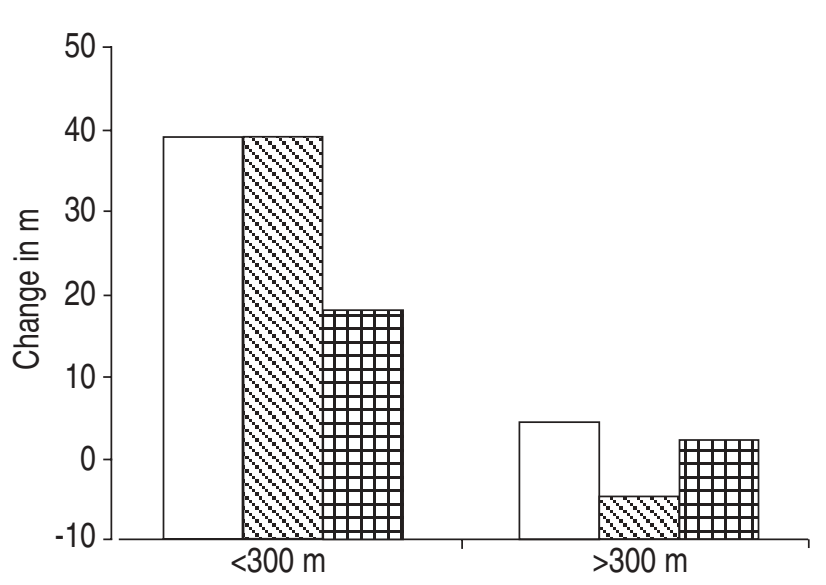

Fig. 1.-Mean change from baseline to 3 months in distance covered in the shuttle walking test. Mean baseline value in the $\leqslant 300 \mathrm{~m}$ stratum was $203 \mathrm{~m}$ and mean baseline in the $>300 \mathrm{~m}$

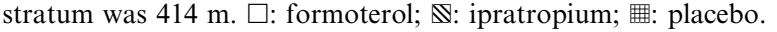

using these measures as covariates. None of these variables was found to have a statistically significant influence on the results.

\section{Dyspnoea during the shuttle walking test}

There was a wide variation in the Borg dyspnoea score after the SWT, indicating a great variance in individual perception of dyspnoea after exertion. No significant differences were seen between the treatment groups. In the placebo group only, there was a slight but significant increase in the score at the end of treatment compared with the randomisation visit (table 4). This indicates that the patients experienced almost the same degree of dyspnoea after the SWT throughout the study.

\section{Spirometry}

Spirometry (FEV1 and FVC) was assessed before the SWT at each clinic visit. FEV1 and FVC values were significantly higher with both formoterol and ipratropium bromide than with placebo after 12 weeks (table 4). After 4 weeks, formoterol gave a significantly greater improvement in FEV1 than ipratropium bromide but after 12 weeks there was no longer a statistically significant difference. For FVC, there was no significant difference between the active treatments at any time point.

\section{Arterial blood gas tensions}

For $\mathrm{Pa}, \mathrm{O}_{2}$ values after 12 weeks, neither formoterol nor ipratropium bromide differed statistically significantly from placebo. However, there was a significant difference in favour of formoterol compared with the ipratropium bromide treatment (difference $0.6 \mathrm{kPa}$, 95\% CI: 0.06-0.66).

\section{Diary cards}

Patients measured PEF twice daily, morning and evening, before taking their study medication. Change in morning PEF was significantly greater with both active treatments than with placebo: the mean increase compared with placebo was $16.2 \mathrm{~L} \cdot \mathrm{min}^{-1}$ (95\% CI: 8.4-23.9) after formoterol and $8.0 \mathrm{~L} \cdot \mathrm{min}^{-1}$ (0.3-15.7) after ipratropium bromide. Additionally, formoterol caused a significantly higher increase than ipratropium bromide, the difference being $8.2 \mathrm{~L} \cdot \mathrm{min}^{-1}$ (0.5-15.8). For evening PEF, both active treatments showed significantly higher values than placebo: formoterol $14.3 \mathrm{~L} \cdot \mathrm{min}^{-1}(5.7-22.9)$ and ipratropium bromide $15.7 \mathrm{~L} \cdot \mathrm{min}^{-1}(7.2-24.3)$, with no difference between the active treatments.

As relief medication the patient could use any shortacting $\beta_{2}$-agonist, which means that the number of inhalations is not dose-adjusted. The mean total daily relief consumption during the last 2 months of treatment was 3.6 inhalations in the formoterol group, 3.9 inhalations in the ipratropium bromide group and 4.7 inhalations in the placebo group. Less than $20 \%$ was consumed during night-time. Formoterol caused a significant reduction in daytime use compared with placebo, but no significant difference in night-time use.

COPD symptoms, dyspnoea and cough were recorded in the morning and evening; sleep disturbances were also recorded. Both formoterol and ipratropium bromide caused a significant reduction in daytime dyspnoea compared with placebo (table 4). Daytime cough was significantly reduced in the ipratropium bromide group (table 4) relative to placebo. For night-time symptoms, no statistically significant differences were found.

\section{Quality of life}

There were no significant differences between the treatment groups in the changes from baseline in total SGRQ score. The difference between baseline and the 3 monthy assessment was $1.5 \%$ units $(95 \% \mathrm{CI}$ $-0.8-3.7)$ for placebo, $0.0 \%$ units $(95 \% \mathrm{CI}-2.2-2.2)$ for formoterol and $-0.5 \%$ units $(95 \%$ CI $-2.8-1.7)$ for ipratropium bromide. Among the three subdomains, only the symptom domain showed a significant difference between the treatment groups, ipratropium bromide being $9.9 \%$ units $(4.2-15.7)$ better than placebo and $5.7 \%$ units $(0.04-11.4)$ better than formoterol.

\section{Adverse events}

A total of 253 adverse events were reported during randomised treatment: 74 in the placebo group, 85 in the formoterol group and 94 in the ipratropium bromide group (NS). The number of patients reporting adverse events classified as related to COPD were 23 in the placebo group, 23 in the formoterol group and 22 in the ipratropium bromide group. In general, the reported adverse events had a similar distribution between the treatment groups, though some symptoms 
like coughing and headache were only reported for formoterol and ipratropium bromide. There were seven serious adverse events in the placebo group (pneumonia (two), COPD deterioration (two), fracture (one), viral infection (one), infection (one)), three in the formoterol group (pneumothorax (one), COPD deterioration (one), retinal detachment (one)) and three in the ipratropium bromide group (pneumonia (two), hepatic neoplasm (one)). In 37 cases, the adverse event led to withdrawal from the trial, in 24 cases due to deterioration in COPD as assessed by the investigator. Withdrawals due to adverse events other than deterioration in COPD were fracture (one), coughing (one), pneumonia (one), viral infection (one) in the placebo group, erythematous rash and pruritus (one), gastroenteritis (one), abdominal pain (one), diarrhoea (one), rheumatoid arthritis (one), respiratory infection, leucocytosis and COPD (one), pneumothorax (one) in the formoterol group, and in the ipratropium bromide group artial fibrillation (one), bronchitis (one). In all, 13 patients discontinued the trial due to adverse advents other than COPD deterioration, seven in the formoterol group, four in the placebo group and two in the ipratropium bromide group.

The mean changes were small for all laboratory variables and there was no indication of any influence of the investigational products. The changes in heart rate, pulse rate, systolic and diastolic blood pressures and electrocardiogram were small and no clinically important pattern was discernible.

\section{Discussion}

This study investigated the effects of formoterol and ipratropium bromide in patients with moderate-tosevere COPD, characterised by very low reversibility. The selected patients had a mean FEV1 of $40 \%$ predicted normal after bronchodilatation, and their mean walking distance in SWT was $\sim 300 \mathrm{~m}$, i.e. they were considered to be in a moderately to severely impaired state $[2,12,13]$. Their mean bronchodilator reversibility was $6 \%$ of predicted normal value, showing that the likelihood of a response to bronchodilators was very low. The rationale for choosing the patient group, with the smallest possible bronchodilator response, was to evaluate whether these patients benefit from a medication they are often prescribed with little knowledge of what impact to expect on exercise capacity and symptoms or if bronchodilator treatment should be discouraged.

As expected, both formoterol and ipratropium bromide had significant effects on lung function measurements and symptoms. However, although $41 \%$ of formoterol-treated patients and $38 \%$ of the ipratropium bromide group achieved a clinically significant improvement $\geqslant 30 \mathrm{~m}$ in exercise capacity as measured by the SWT (which was defined as a clinically significant change for this study), the effect was not statistically significant.

The exercise outcome chosen in this study was the SWT, which has been useful for assessment of improvement in COPD rehabilitation programmes
[13]. Furthermore, in a previous pilot study of 20 patients, significant immediate effects on exercise capacity were seen in a parallel-group comparison between formoterol and placebo. Using data from that study, a residual SD of $50 \mathrm{~m}$ could be expected. A power calculation was performed showing that with 45 patients in each group, there would be an $80 \%$ chance of detecting a true difference between two treatments of $30 \mathrm{~m}$ using a t-test at a 5\% significance level. In the present study, the residual SD was somewhat higher, i.e. $56 \mathrm{~m}$, and the mean difference between active and placebo treatment was $\sim 20 \mathrm{~m}$. The expectation of finding an improvement of $30 \mathrm{~m}$ was based on findings in rehabilitation studies. Some recent studies have found that rehabilitation can increase the mean shuttle walking distance 50-70 m in moderate-to-severe COPD $[16,17]$. The less than expected increase in walking distance in this study made it impossible to find a significant effect on exercise capacity.

Analysis after stratification of the patients in the study shows that a change in mean walking distance was seen only in those with low exercise capacity at entry $(\leqslant 300 \mathrm{~m})$; patients with a higher capacity did not show any improvement. This is in agreement with recent data, which showed patients with more severe COPD (baseline SWT of $191 \mathrm{~m}$ ) to increase their walking distance by $88 \mathrm{~m}$ whereas patients with better capacity or very severe COPD showed no improvement after rehabilitation [17]. Thus, the window for demonstrating an effect with this test appears small, and it also seems probable that the effect achieved in a long-term study using a bronchodilator is less pronounced on the exercise capacity than in a rehabilitation programme. In addition, a similar study of salmeterol showed no significant effect on the 6-min walking test compared with placebo [9]. A possible explanation for this difference between the two types of intervention is that, with rehabilitation, there is also the training of muscles, balance etc., needed to significantly improve exercise capacity.

In this study, the only significant difference seen in the SWT was the difference in favour of formoterol compared with placebo after 4 weeks of treatment. Later in the study, this difference was not significant. It is unlikely that the explanation for this would be development of tolerance to formoterol as the time trend with a remaining effect after 4 weeks, but not after 8 weeks, fits poorly with the small tolerance development seen with $\beta_{2}$-agonists in protection against provocations and possibly bronchodilation $[8,18,19]$. In this situation, tolerance is fully developed after a few days for up to 2 weeks. A more plausible explanation would be decreasing compliance with formoterol, which was given at a relatively high dose. This is supported by reduced improvement in FEV1 and the increased number of drop-outs in the formoterol group.

At the end of the SWT, the mean level of the Borg score, used to evaluate the severity of dyspnoea, was $\sim 6$, and remained unchanged throughout the study for all treatments. Hence, the patients worked with the same level of exertion at the different exercise tests, a prerequisite for evaluation of this test. Pulse rates 
were also similar after the different treatments, with a mean level of $\sim 105$ beats $\cdot \mathrm{min}^{-1}$.

COPD symptoms were recorded in diary cards. Daytime dyspnoea symptoms decreased significantly with both active treatments, with no difference between them. It therefore seems logical to use these bronchodilating drugs for decreasing levels of dyspnoea. For night-time symptoms, formoterol had a numerically more pronounced effect than ipratropium bromide, which can probably be explained by the longer duration of effect for formoterol.

As expected, no improvement in the total score of the QoL measurements in such impaired patients was seen. A similar study with salmeterol (50 $\mu \mathrm{g}$ and $100 \mu \mathrm{g}$ b.i.d.) only showed an improved QoL, using the SGRQ, for the low dose of salmeterol compared with placebo. This was not the case for the high dose [10]. The high dose of salmeterol had a similar potency to the dose of formoterol given in this study [20, 21]. Likewise, in a study with formoterol $12 \mu \mathrm{g}$ and $24 \mu \mathrm{g}$ b.i.d the lower formoterol dose had a better impact on QoL [22]. Hence, the lack of effect on QoL with the high dose of formoterol may have been due to sideeffects. The present trial thus confirms the lack of effect or smaller effect of a high dose of long-acting $\beta_{2}$-agonists in COPD on QoL $[10,22]$. The authors decided to dose ipratropium bromide three- times daily although a four-times daily regimen represents a better adjustment to its short duration of action $[22,23]$. It is difficult to adhere to a four-dose daily regimen and the selected dosing scheme with a double dose $(80 \mu \mathrm{g})$ t.i.d was considered an adaptation to current practice in order to obtain a better patient compliance.

One surprise finding in this study was the difference between formoterol and ipratropium bromide regarding withdrawals. This difference was mainly seen in the patients with the lowest exercise capacity $(\leqslant 300 \mathrm{~m}$ walking distance). Factors to be considered are the choice of a relatively high dose of formoterol, which might possibly result in more side-effects and the effect of discontinuation of ipratropium bromide from the start of the trial.

Lung function measurements showed improvements with the active treatments despite very low reversibility in the patients. Similar findings have been described in short-term studies of salmeterol, formoterol and anticholinergics in COPD [24, 25]. Also, in long-term studies with salmeterol and formoterol, there were significant effects on spirometry measurements $[9,22,23,26]$. In fact, the statistically strongest difference between active and placebo treatments was seen for these variables in the present study, even though the differences in absolute terms were small: increases of $4.6 \%$ and $2.4 \%$ of predicted FEV 1 normal value in the formoterol and ipratropium bromide groups, respectively, compared with placebo. Moreover, PEF measurements from the diary cards clearly showed significantly higher values after active treatments, with mean differences between active and placebo treatments of up to $16 \mathrm{~L} \cdot \mathrm{min}^{-1}$. For morning PEF, there was a significant difference between the active treatments in favour of formoterol, probably as a carry-over from the evening dose due to the longer duration of effect. There were no differences in evening PEF, possibly because the measurement was taken closer to the last inhaled dose. In a recent study of COPD patients, salmeterol showed better improvement in FEV1 than ipratropium bromide but the difference occurred in the more reversible patients only; no difference was observed between treatments in the least reversible patients [26].

Treatments with $\beta_{2}$-agonists can increase ventilation/perfusion mismatch, especially with systemic treatment, so blood gases were measured in this study [27]. There was no significant difference for either of the active treatments compared with placebo. Oxygen tension was significantly higher after formoterol than ipratropium bromide, providing further evidence that inhaled treatment with formoterol does not cause any deterioration in blood gases in patients with COPD.

To conclude, this study shows that in moderate-tosevere chronic obstructive pulmonary disease patients, formoterol and ipratropium bromide have similar beneficial effects on lung function measurements and symptoms, with the formoterol group showing a somewhat longer duration of bronchodilation. The limited effect on exercise capacity of bronchodilators in chronic obstructive pulmonary disease underlines the fact that rehabilitation is the major means to obtain improvement in exercise capacity. The high dose of formoterol given in this study, and possibly reduced compliance, could explain the difference in withdrawal rate compared with ipratropium bromide. The lack of effect on quality of life for either treatment might at least partially be explained by the severity of chronic obstructive pulmonary disease with little or no reversibility in these patients. The high dose of formoterol could also be an explanation for its lack of effect on quality of life. The trial showed that despite the fact that some improvement in exercise capacity was found in patients with the lowest exercise capacity only, as a whole this group improved in symptoms and lung function. Even in this patient group a trial of either bronchodilator can thus be considered justified.

\section{References}

1. British Thoracic Society. BTS guidelines for the management of chronic obstructive pulmonary disease. Thorax 1997; 52: Suppl. 5, S1-S28.

2. Siafakas N, Vermeire P, Pride N, et al. Optimal assessment and management of patients with chronic obstructive pulmonary disease (COPD). Eur Respir $J$ 1995; 8: 1398-1420.

3. American Thoracic Society, Boards of Directors. Standards for the diagnosis and care of patients with chronic obstructive pulmonary disease (COPD). Am J Respir Crit Care Med 1995; 152: S77-S120.

4. Vestbo J, Sörensen T, Lange P, Brix A, Torre P, Viskum K. Long-term effect of inhaled budesonide in mild and moderate chronic obstructive pulmonary disease: a randomized controlled trial. Lancet 1999; 353: $1819-1823$

5. Pauwels R, Löfdahl C-G, Laitinen L, Schouten J, Postma D, Pride N. Long-term treatment with inhaled budesonide in persons with mild chronic obstructive 
pulmonary disease who continue smoking. $N$ Engl J Med 1999; 340: 1948-1953.

6. Ikeda A, Nishimura K, Koyama H, Izumi $T$. Bronchodilating effects of combined therapy with clinical dosages of ipratropium bromide and salbutamol for stable COPD: comparison with ipratropium bromide alone. Chest 1995; 107: 401-405.

7. Hay JG, Stone P, Carter J, et al. Bronchodilator reversibility, exercise performance and breathlessness during corridor walking in chronic obstructive pulmonary disease: effect of oxitropium bromide. Eur Respir $J$ 1992; 5: 659-664.

8. Pauwels RA, Löfdahl C-G, Postma DS, et al. Effect of inhaled formoterol and budesonide on asthma exacerbations. N Engl J Med 1997; 337: 1405-1411.

9. Boyd G, Morice A, Pounsford J, Siebert M, Peslis N, Crawford C. An evaluation of salmeterol in the treatment of chronic obstructive pulmonary disease (COPD). Eur Respir J 1997; 10: 815-821.

10. Jones P, Bosh T. Quality of life changes in COPD patients treated with salmeterol. Am J Respir Crit Care Med 1997; 155: 1283-1289.

11. Seberová E, Andersson A. Oxis $\mathbb{R}$ (formoterol given by Turbuhaler $($ ) showed as rapid an onset of action as salbutamol given by pMDI. Respir Med 2000; 94: 607-611.

12. Singh SJ, Morgan M, Scott S, Walters D, Hardman A. Development of a shuttle walking test of disability in patients with chronic airways obstruction. Thorax 1992; 47: 1019-1024.

13. Singh S, Morgan M, Hardman A, Rowe C, Bardsley $\mathrm{P}$. Comparison of oxygen uptake during a conventional treadmill test and the shuttle walking test in chronic airflow limitation. Eur Respir J 1994; 7: 2016 2020.

14. Borg G. Psychophysical bases of perceived exertion. Med Sci Sports 1982; 14: 377-381.

15. Jones P, Quirk F, Baveystock C. The St George's Respiratory Questionnaire. Respir Med 1991; 85: 25-31.

16. Singh SJ, Smith DL, Hyland ME, Morgan MD. A short outpatient pulmonary rehabilitation programme: immediate and longer term effects on exercise performance and quality of life. Respir Med 1998; 92: 1146-1154.

17. Wedzicha JA, Bestall JC, Garrod R, Garnham R, Paul EA, Jones PW. Randomized controlled trial of pulmonary rehabilitation in severe chronic obstructive pulmonary disease patients, stratified with the MRC dyspnoea scale. Eur Respir J 1998; 12: 363-369.

18. Yates D, Sussman H, Shaw M, Barnes P, Chung K. Regular formoterol treatment in mild asthma. Effect on bronchial responsiveness during and after treatment. Am J Respir Crit Care Med 1995; 152: 1170 1174.

19. Cheung D, Timmers $\mathrm{M}$, Zwinderman A, Bel E, Dijkman J, Sterk P. Long-term effects of a longacting beta 2-adrenoceptor agonist, salmeterol, on airway hyperresponsiveness in patients with mild asthma. N Engl J Med 1992; 327: 1198-1203.

20. Ullman A, Svedmyr N. Salmeterol, a new long acting beta 2 adrenoceptor agonist: comparison with salbutamol in adult asthmatic patients. Thorax 1988; 43: 674-678.

21. Löfdahl C-G, Svedmyr N. Formoterol fumarate, a new beta 2-adrenoceptor agonist. Acute studies of selectivity and duration of effect after inhaled and oral administration. Allergy 1989; 44: 264-271.

22. Dahl R, Greefhorst LA, Nowak D, et al. Inhaled formoterol dry powder versus ipratropium bromide in chronic obstructive pulmonary disease. Am J Respir Crit Care Med 2001; 164: 778-784.

23. Rennard SI, Anderson W, zuWallack R, et al. Use of long-acting inhaled $\beta_{2}$-adrenergic agonist, salmeterol, in patients with chronic obstructive pulmonary disease. Am J Respir Crit Care Med 2001; 163: 10871092.

24. Cazzola M, Imperatore F, Salzillo A, et al. Cardiac effects of formoterol and salmeterol in patients suffering from COPD with preexisting cardiac arrythmias and hypoxemia. Chest 1998; 114: 411-445.

25. Cazzola M, Di Perna F, Noschese P, et al. Effects of formoterol, salmeterol or oxitropium bromide on airway responses to salbutamol in COPD. Eur Respir J 1998; 11: 1337-1341.

26. Mahler DA, Donohue JF, Barbee RA, et al. Efficacy of salmeterol xinafoate in the treatment of COPD. Chest 1999; 115: 957-965.

27. Williams A, Weiner C, Reiff D, Swenson E, Fuller R, Hughes J. Comparison of the effect of inhaled selective and non-selective adrenergic agonists on cardiorespiratory parameters in chronic stable asthma. Pulm Pharmacol 1994; 7: 235-241. 